\section{The Physikalisch-Technische Anstalt}

ELSEWHERE in this issue we record the death of Prof. W. Kösters, the first president of the Physikalisch-Technische Anstalt, which is situated a few miles west of Brunswick in the British Zone, and is successor to the Physikalisch-Technische Reichsanstalt, of Berlin-Charlottenburg. During the War, many departments of the Physikalisch-Technische Reichsanstalt had been dispersed to various university towns, the major part to Weida in Thuringia (Russian Zone). Some 80 per cent of its buildings at Charlottenburg were eventually destroyed by bombing. Although, therefore, the move to new premises was dictated by necessity, it brought with it many advantages. The Physikalisch-Technische Reichsanstalt had outgrown its Charlottenburg premises, and these, being situated in a municipal neighbourhood, had as time went on become increasingly unsuited for delicate scientific measurements. Following agreement between the three Western Occupying Powers, the Scientific Research Branch of the British Element of the Control Commission for Germany was made responsible in 1948 for the rehabilitation of most of the departments remaining in Berlin, and the scattered elements elsewhere, as the Physikalisch-'Technische Anstalt. This was part of the policy of the Scientific Research Branch, of encouraging German research of a peaceful nature as opposed to the main policy of controlling and preventing research for war purposes. A site on the old Luftfahrtforsehungsanstalt Hermann Goering near Brunswick in Lower Saxony was placed at the disposal of the Physikalisch-Technische Anstalt, on condition that the extensive demilitarization of the buildings with war potential was undertaken. The Luftfahrtforschungsanstalt had escaped destruction during the War probably because it is situated in a thick wood and was provided with elaborate camouflage. The Deutsche Physikalische Gesellschaften in the British Zone (which at their recent annual meeting held in Bad Nauheim were reconstituted as the Verband der Deutschen Physikalischen Gesellschaften) appointed a committee consisting of Profs. Heisenberg, Kopfermann, von Laue and Pohl to advise on the selection of a president, and the choice fell on Kösters. Hitherto the policy had always been to recruit the president from outside the PhysikalischTechnische Reichsanstalt.

\section{International Standards and Use of Insecticides}

THREE subjects are, in the main, dealt with in the report on the first session of the Expert Committee on Insecticides of the World Health Organization (Technical Report Series, No. 4 ; pp. 46 ; Geneva: World Health Organization; London: H.M. Stationery Office, $1950 ; 2 s .3 d . ; 30$ cents). The first concerns the specifications of international standards for insecticides and their formulations for use against vectors of malaria, together with specifications for standard spraying equipment for malaria control and its adaptability to regional conditions. The second is the elaboration of a standard method for the elimination of insect vectors of disease from ships and aircraft, while the third is the recommendation of measures that might be given general application for the prevention of the introduction of anopheline mosquitoes into areas free or freed from them. Detailed specifications are laid down for DDT, together with the methods for determining the required chemical and physical characteristics of technical grade DDT, Other insecticides are left in abeyance. General requirements for formulations are set out. Specifications for hand and compression sprayers are given in some detail, and technical improvements recommended. Methods of 'disinsection' of ships and aircraft for quarantine purposes are described using DDT and the pyrethrins, and the recommendations of the committee on the composition, dosage and forms of distribution of the insecticide in the aircraft are given. The measures that, in the opinion of the committee, should be considered in the endeavour to prevent re-introduction of anopheline mosquitoes in an area freed from them are then described. Brief consideration is given to the question of the interchange of information and literature, the waiving of customs duties on material for insect control, the functions of the World Health Organization panel of experts on insecticides, the toxicity of DD'T to man, and rodenticides.

\section{James Young}

AN article by A. D. Cummings in the October 1950 issue of Discovery $(11$, No. 10) gives details of how the petroleum industry was started in Great Britain by James Young just over a hundred years ago. In 1847 Young received a letter from Lyon Playfair, chemist to the Geological Survey, explaining that a spring of "mineral naptha" had been discovered on an estate near Alfreton, Derbyshire, and inviting Young to develop an industry which would provide a lamp oil cheaper than the sperm oil then in use. Young, who was then works manager to a chemical firm in Manchester, invited his employers to promote the project; the idea was considered too trivial to discuss. Yet, within twenty years, Young was able to retire with a comfortable fortune and, after several disappointments, was able to launch an industry which is still working profitably. An interesting sequel to Playfair's original letter was that no further oil discovery was made in Great Britain until 1918, when a small quantity of oil was discovered near Chesterfield.

\section{Taxonomy of Tropical African Plants}

SHORTLY before the appearance of the paragraph under this title in Nature of December 2, p. 936, the secretary of the Association pour l'stude taxonomique de la Flore d'Afrique tropicale, Dr. J. Léonard, tendered his resignation. No official Belgian representative was present at the inaugural meeting. In consequence of the above resignation a meeting was held at Kew on December 14 to elect a new secretary. Twenty-one botanists were present, including taxonomists from the Anglo-Egyptian Sudan, Austria, Portugal and the United States of America. Letters in support of the aims of the Association had been received from botanists in Belgium, France, Germany, Italy, Nigeria and Sweden. By a unanimous vote of those present, Mr. R. D. Meikle, of the Royal Botanic Gardens, Kew, was elected secretary, and all communications regarding the Association should be addressed to him.

\section{Physical Society's Annual Exhibition}

THE thirty-fifth annual Exhibition of Scientific Instruments and Apparatus arranged by the Physical Society will be held during April 6-11, excluding Sunday, in the Royal College of Science Main Building, Imperial Institute Road, London, S.W.7, and also in the Huxley Building, Exhibition Road (opposite the Science Museum). All tickets will be valid for entry into both buildings. The first day will be reserved 